\title{
Isolated congenital left ventricular diverticulum
}

\author{
Zafer Isilak, ${ }^{1}$ Onur Sinan Deveci, ${ }^{1}$ Namık Ozmen, ${ }^{1}$ Mehmet Incedayi ${ }^{2}$
}

'Department of Cardiology, GATA Haydarpasa Teaching Hospital, Istanbul, Turkey ${ }^{2}$ Department of Radiology, GATA Haydarpasa Teaching Hospital, Istanbul, Turkey

\section{Correspondence to Dr Mehmet Incedayi,} m_incedayi@yahoo.com
To cite: Isilak Z, Deveci OS, Ozmen N, et al. BMJ Case Reports Published online: [please include Day Month Year] doi:10.1136/bcr-2012008338

\section{DESCRIPTION}

A 55-year-old man was admitted to our hospital with atypical chest pain. The patient's medical history included moderate dyslipidemia. Patient's blood pressure was $130 / 85 \mathrm{~mm} \mathrm{Hg}$ and his pulse was $82 / \mathrm{min}$ and rhythmic. Physical examination was normal. Normal sinus rhythm was determined in the 12 lead surface ECG and $24 \mathrm{~h}$ ambulatory ECG recordings were also normal. Transthoracic echocardiography (TTE) revealed an ejection fraction of $65 \%$. A contractile apical left ventricle diverticulum was detected on modified apical four-chamber and apical two-chamber windows with TTE (figure 1A). Color doppler and color flow M-mode echocardiography showed that blood flow was entering towards the diverticulum from left ventricle during diastole and was flowing out during systole (figure 1B-D). No other intracardiac congenital abnormalities were found in TTE. ECG-gated coronary CT angiography was also performed and coronary arteries were normal. Long axis coronary multislice tomography images revealed focal outpouching in apical wall of left ventricle. A diverticulum with a narrow neck localised in the left ventricular apex causing contour bulging was seen (figure 2A). Three-dimensional volume-rendering image showed apical wall diverticulum of left ventricle (figure 2B,C). Surgical resection was not indicated. Treatment with acetyl salicylic acid was started to reduce incidence of thromboembolism, atorvastatin was started for hyperlipidemia and routine control was planned.

Congenital diverticulum of the ventricle is a rare cardiac malformation. It may present as an isolated disorder or may be associated with other cardiac abnormalities such as Cantrell's syndrome. ${ }^{1}$ Cantrell's syndrome is usually detected in children and is characterised by congenital defects involving the abdominal wall, sternum, diaphragm, pericardium and heart. At least nine patients, all newborn, with associated limb malformations have been described. $^{2}$ In $30 \%$ of the cases, left ventricular diverticulum is not associated with congenital malformations and is referred to as isolated left ventricular diverticulum. Clinically, it has been reported that it can lead to chest pain, arrhythmias, cardiac rupture and sudden death, although frequently the course is asymptomatic.

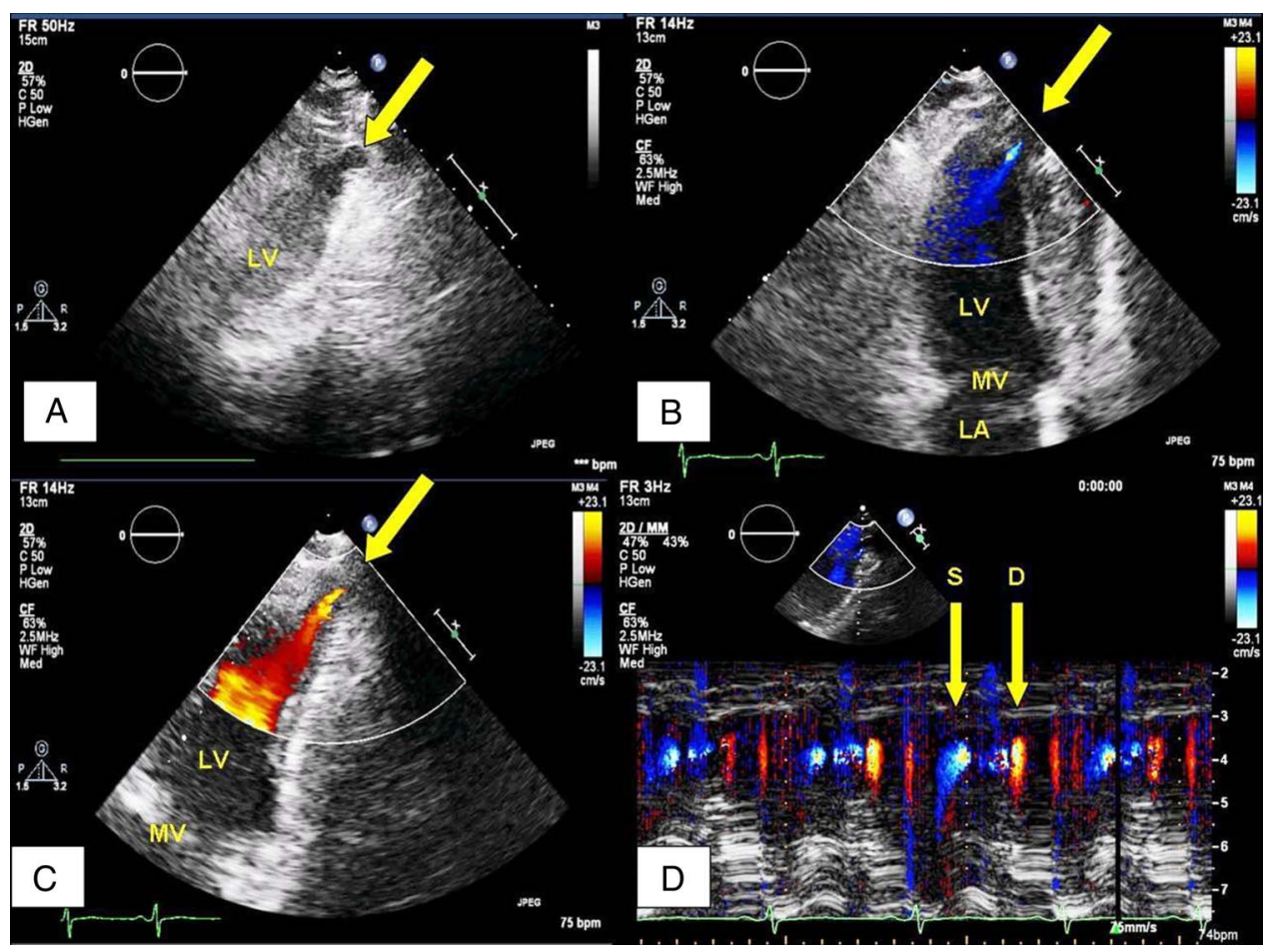

Figure 1 (A) Modified apical four-chamber window of transthoracic echocardiography showing apical left ventricular diverticulum (arrow). (B-D) Color doppler and color flow M-mode echocardiography showed that blood flow was entering towards the diverticula from left ventricle during diastole and was flowing out during systole $(S$, systole; $D$, diastole; MV, mitral valve; LV, left ventricle; LA, left atrium). 
Figure 2 (A) Long-axis coronary multislice tomography image reveals focal outpouching in apical wall of left ventricle. Note the aneurysm with a narrow neck of the left ventricle causing contour bulging (arrow). (B) Three-dimensional (3D) volume-rendered imaging. Apical diverticula of left ventricle (arrow) and (C) 3D volume-rendering image shows that the apical diverticulum was filled with contrast material (arrow).

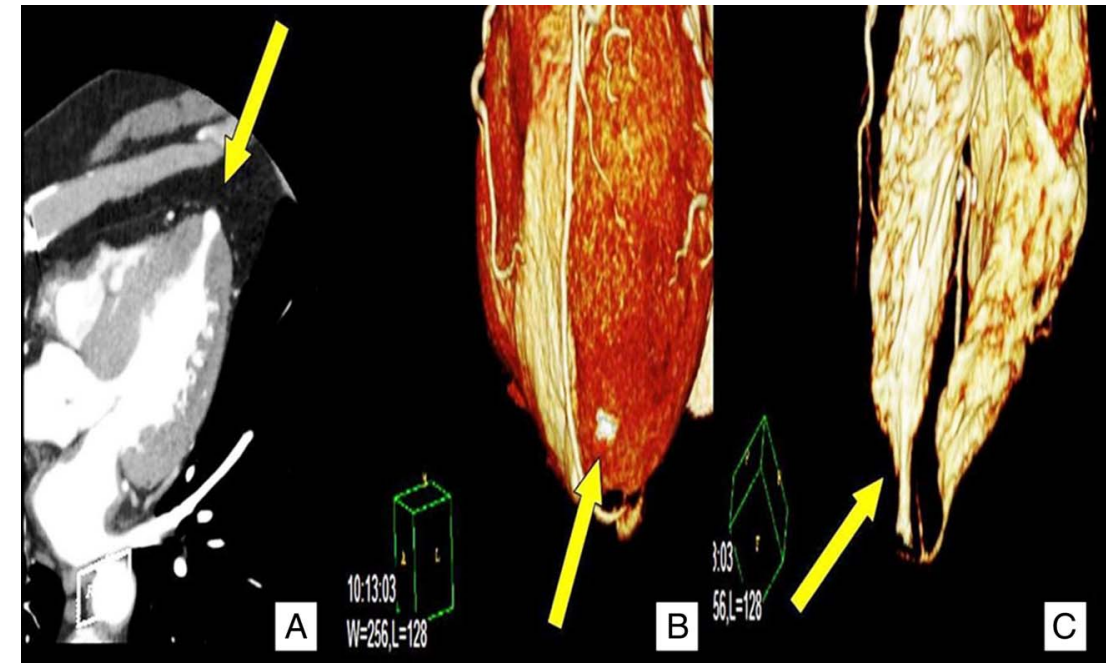

Competing interests None.

Patient consent Obtained.

Provenance and peer review Not commissioned; externally peer reviewed.

\section{REFERENCES}

1 Cantrell JR, Haller JA, Ravitch MM. A syndrome of congenital defects involving the abdominal wall, sternum, diaphragm, pericardium and heart. Surg Gynecol Obstet 1958;107:602-14.

2 Vazquez-Jimenez JF, Muehler EG, Daebritz $\mathrm{S}$, et al. Cantrell's syndrome: a challenge to the surgeon. Ann Thorac Surg 1998;65:1178-85.

Copyright 2013 BMJ Publishing Group. All rights reserved. For permission to reuse any of this content visit http://group.bmj.com/group/rights-licensing/permissions.

BMJ Case Report Fellows may re-use this article for personal use and teaching without any further permission.

Become a Fellow of BMJ Case Reports today and you can:

- Submit as many cases as you like

- Enjoy fast sympathetic peer review and rapid publication of accepted articles

- Access all the published articles

- Re-use any of the published material for personal use and teaching without further permission

For information on Institutional Fellowships contact consortiasales@bmjgroup.com

Visit casereports.bmj.com for more articles like this and to become a Fellow 